and (2) our failure to observe any other strong absorption lines over a tuning range $>0.5 \mathrm{~cm}^{-1}$ centered on this line.

${ }^{13}$ E. K. Plyler, A. Panti, L. R. Blaine, and E. D. Tidwell, J. Res. Natl. Bur. Std. (U. S. ) 64A, 29 (1960).
${ }^{14}$ Reference $1, \mathrm{p} .31$.

${ }^{15}$ D. A. Draeger and D. Williams, J. Opt. Soc. Am. 58, 1399 (1968).

${ }^{16}$ Reference 1, p。 201.

\title{
Preferential Oxidation of Fe in Permalloy Films*
}

\author{
C.H. Bajorek, M-A. Nicolet, and C.H. Wilts \\ California Institute of Technology, Pasadena, California 91109
}

(Received 3 May 1971)

\begin{abstract}
On the basis of He-ion backscattering, x-ray fluorescence, and complementary measurements, it is unambiguously established for the first time that the oxide layer on the surface of oxidized $81 \% \mathrm{Ni}-19 \% \mathrm{Fe}$ evaporated films is predominantly Fe-oxide. Extrapolation of results for pure iron films indicates that the oxide is most likely antiferromagnetic $\alpha-\mathrm{Fe}_{2} \mathrm{O}_{3}$. On the basis of ferromagnetic resonance measurements, it is concluded that the oxide negligibly affects the pinning of the bulk spins at the film-oxide interface.
\end{abstract}

Oxidized thin magnetic films are known to exhibit anomalous magnetic characteristics. These have received considerable attention in the study of lowtemperature hysteresis and resonance behavior of oxidized $\mathrm{Ni}-\mathrm{Fe}$ alloy films. ${ }^{1-4}$ The anomalies are believed to be associated with an interaction between the ferromagnetic bulk of a film and its surface oxide, which is presumed to be antiferromagnetic. A complete understanding of these effects requires proper identification of the oxide. Unfortunately, previous attempts to characterize the oxide of $\mathrm{Ni}-\mathrm{Fe}$ alloy films have been inconclusive. Some authors imply it could be $\mathrm{Fe}_{3} \mathrm{O}_{4},{ }^{1}$ others $\mathrm{FeO},{ }^{2,3}$ and the only direct attempt to identify the oxide by electron-diffraction studies ${ }^{4}$ claims the presence of $\alpha-\mathrm{Fe}_{2} \mathrm{O}_{3}$ in thin oxides and its absence in thick oxides. Furthermore, it is unclear whether these conclusions imply the presence or absence of $\mathrm{Ni}$-oxide or a complex $\mathrm{Ni}$ - $\mathrm{Fe}$-oxide.

To resolve this problem we have studied the roomtemperature properties of oxidized Permalloy films by two direct analytical methods: He-ion backscattering and $\mathrm{x}$-ray fluorescence; and by complementary ferromagnetic resonance (FMR), hysteresis loop tracer, and torque-magnetometer measurements.

The 1-cm-diam Ni, Fe, and $\mathrm{Ni}-\mathrm{Fe}$ films, 300 to $2500 \AA$ thick, were evaporated onto glass substrates from inductively heated melts of $83 \% \mathrm{Ni}-17 \% \mathrm{Fe}$ in a vacuum better than $10^{-6}$ Torr. The degree of oxidation was controlled by varying the time and temperature of subsequent anneals of the films in air. The backscattering results were obtained with 2.5 $\mathrm{MeV}$ He ions from a 3-MeV van de Graaff accelerator. ${ }^{5}$ The $x$-ray fluorescence results were obtained with a $50-\mathrm{keV} \mathrm{x}$-ray spectrometer. The resonance measurements were made in a $50-\Omega$ stripline driven by $1-$ to $8-\mathrm{GHz}$ oscillators with a static magnetic field applied parallel and perpendicular to the film plane. The film thicknesses were deduced from magnetic moments measured to $2 \%$ accuracy with a hysteresis loop tracer and a torque magnetometer.

In the backscattering experiment, monoenergetic He ions forming a well-collimated beam of approximately $2 \times 2 \mathrm{~mm}^{2}$ impinge on the film surface. The He ions scattered back by collisions with film and substrate nuclei are detected with a Si surface-barrier detector, resolved in energy, and their numbers are recorded with a 400 channel analyzer. Figure 1 shows the results obtained on a pure Ni film (top), a Permalloy film (center), and a pure Fe film (bottom), all on glass substrates, and each before and after partial oxidation. The high-energy edge of each spectrum is replotted on an expanded scale on the right. This edge is generated by He ions scattered back from regions near the front surface of the film. Ions scattered back from deeper within the film have lower energies because of losses suffered in traversing the dense film medium of the target. The slope of the edge reflects the resolution of the system. The signals generated by the glass substrates are not shown in this figure for clarity. Their contributions appear at lower energies because of the smaller masses of the atoms composing them. For the same reason, the edge of the pure $\mathrm{Fe}$ film lies at slightly lower energy (approximately 20 $\mathrm{keV}$ ) than that of the pure Ni film. These two edges do not change their positions upon oxidation, since the oxides contain metal atoms as well but in a modified structural configuration. This change in structure results in a change in the height of the spectra below the edge. The nonuniformity of these two spectra with depth also shows that the process of oxidation is incomplete in both cases. On the other hand, note that oxidation does change the position of the edge for the Permalloy film. Before oxidation, the edge coincides with that of $\mathrm{Ni}$, as expected from the presence of $\mathrm{Ni}$ atoms in the Permalloy film. After oxidation, however, the edge recesses to that of $\mathrm{Fe}$, indicating that $\mathrm{Fe}$ is by far the main constituent of the uppermost layer (oxide) of the film. To be consistent with the spectra shown, the oxide 


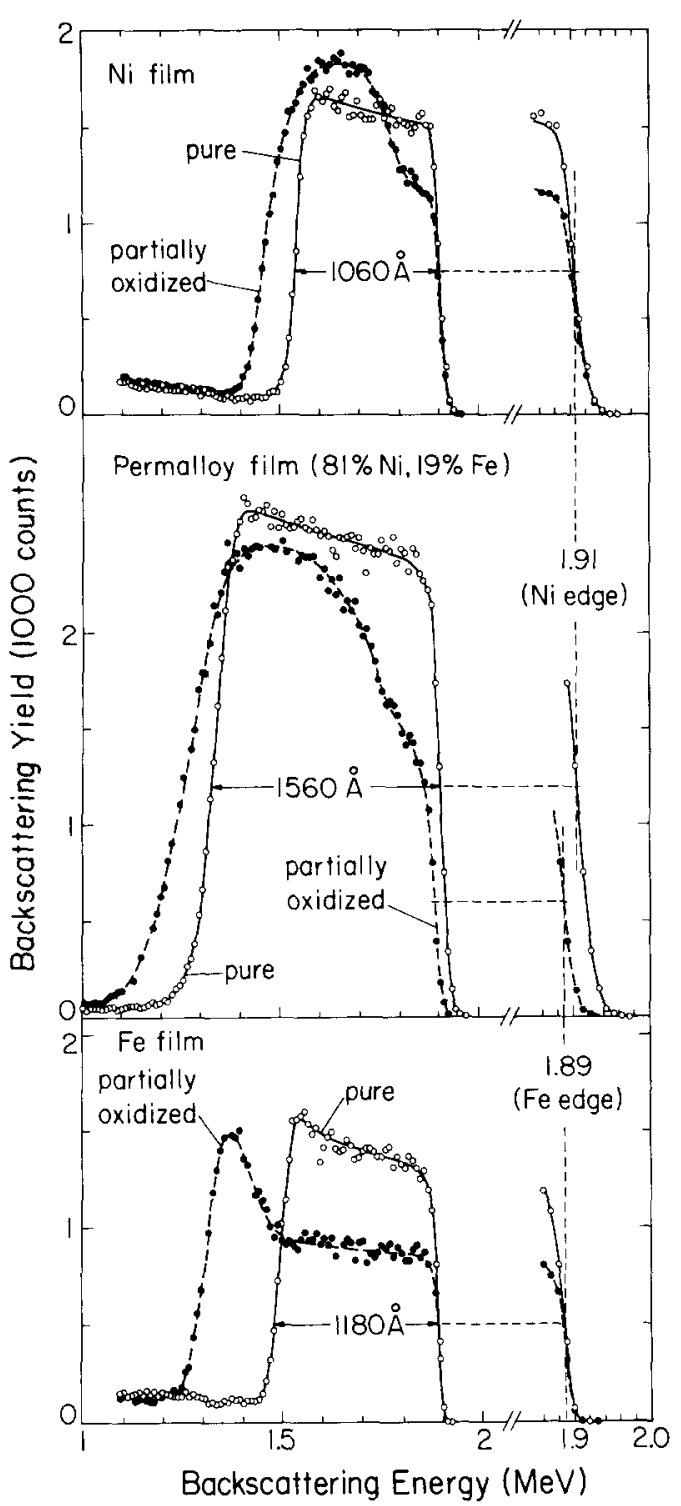

FIG. 1. Backscattering spectra of $2.5-\mathrm{MeV}{ }^{4} \mathrm{He}^{+}$ions impinging on thin films of pure Ni (top), $81 \% \mathrm{Ni}-19 \%$ Fe (center), and pure $\mathrm{Fe}$ (bottom) on glass substrates, each prior to and after partial oxidation. The backscattering angle is $164^{\circ}$, the integrated ion current is $18 \mu \mathrm{C}$ for $\mathrm{Ni}$ and $\mathrm{Fe}$, and $15 \mu \mathrm{C}$ for Permalloy. The Ni film was oxidized in air at $400^{\circ} \mathrm{C}$ for $15 \mathrm{~min}$, the Permalloy film at $500^{\circ} \mathrm{C}$ for $15 \mathrm{~min}$, and the Fe film at $400^{\circ} \mathrm{C}$ for 1 min. Upon oxidation, the high-energy edges do not shift for the $\mathrm{Ni}$ and $\mathrm{Fe}$ spectra since the oxides also contain the metal atoms. In Permalloy, however, the high-energy edge does shift back to the position of the $\mathrm{Fe}$ edge, indicating the formation of nearly pure $\mathrm{Fe}$-oxide near the film surface.

must contain less than a few percent $\mathrm{Ni}$ over at least the first $200 \AA$ below the film surface. In this case too, the oxidation has not been carried out to completion. Additional experiments have shown that for very light oxidations the high-energy edge of the Permalloy spectrum is seen at positions between those of $\mathrm{Ni}$ and $\mathrm{Fe}$, and that it does not shift beyond the Fe edge for heavier oxidations than shown in this figure.
The predominant formation of Fe-oxide near the surface of oxidized Permalloy films is also directly verified by $x$-ray fluorescence measurements of the change in composition of three films after etching in $\mathrm{HCl}$. A $600-\AA$ film oxidized at $400^{\circ} \mathrm{C}$ for $5 \mathrm{~min}$ and etched for $1 \mathrm{~min}$ in $37 \% \mathrm{HCl}$ shows a $45 \%$ loss of $\mathrm{Fe}$ and only a $5 \%$ loss of $\mathrm{Ni}$; a $2500-\AA$ film oxidized at $500{ }^{\circ} \mathrm{C}$ for $3 \mathrm{~min}$ and etched for $1 \mathrm{~min}$ in $\mathrm{HCl}$ shows a $56 \%$ loss of $\mathrm{Fe}$ with only a $6 \%$ loss of $\mathrm{Ni}$. On the other hand, a 3200- $\AA$ film not oxidized except that occurring at room temperature and etched for 25 min in $\mathrm{HCl}$ shows a $50 \%$ loss of $\mathrm{Fe}$ with a corresponding $48 \%$ loss of $\mathrm{Ni}$. Recognizing that the oxide is dissolved much more rapidly than the metal, these results are consistent with (i) the preferential oxidation of $\mathrm{Fe}$, and (ii) a rather uniform loss of $\mathrm{Fe}$ through the volume of the film as opposed to depletion localized near the film surface, implying a high diffusivity of $\mathrm{Fe}$ in $\mathrm{Ni}$ at these temperatures.

Although in principle the oxide composition near the surface of $\mathrm{Ni}, \mathrm{Fe}$, and Permalloy films can be determined from backscattering spectra, the resolution of the present system only allows the positive exclusion of $\mathrm{Ni}$-oxide for Permalloy films and $\mathrm{FeO}$ for Fe films. However, it does not permit one to distinguish between $\mathrm{FeO}, \mathrm{Fe}_{2} \mathrm{O}_{3}$, and $\mathrm{Fe}_{3} \mathrm{O}_{4}$ for Permalloy films, and $\mathrm{Fe}_{2} \mathrm{O}_{3}$ and $\mathrm{Fe}_{3} \mathrm{O}_{4}$ for $\mathrm{Fe}$ films. On the other hand, the magnetic moments of completely oxidized pure Fe films are less than 1/100 of the corresponding magnetic moments prior to oxidation as measured by a torque magnetometer at $500 \mathrm{Oe}$. The oxides of these films are red. This result suggests the formation of antiferromagnetic $\alpha-\mathrm{Fe}_{2} \mathrm{O}_{3}$ as opposed to black ferrimagnetic $\mathrm{Fe}_{3} \mathrm{O}_{4}$ or ferrimagnetic $\gamma-\mathrm{Fe}_{2} \mathrm{O}_{3}$. It is also consistent with the phase diagram of the $\mathrm{Fe}-\mathrm{O}_{2}$ system which excludes the latter oxides at moderate temperatures in an oxygen-rich atmosphere. ${ }^{6}$ This conclusion is further supported by old metallurgical studies of the hightemperature oxidation of bulk $\mathrm{Fe}$ and $\mathrm{Ni}-\mathrm{Fe}$ alloys which show that the surface oxides in both cases are predominantly $\mathrm{Fe}_{2} \mathrm{O}_{3}$ to depths of several microns. ${ }^{7-9}$ Therefore we conclude that the surface oxide of $\mathrm{Ni}-\mathrm{Fe}$ alloy films is most likely $\alpha-\mathrm{Fe}_{2} \mathrm{O}_{3}$.

Finally, results obtained from FMR measurements on normal and oxidized films 300 to $1700 \AA$ thick are also consistent with the above conclusions and with the presence of negligible pinning of the bulk spins at the film-oxide interface. However, the details of these results will be published elsewhere.

In summary, the results from several direct and indirect analytical methods clearly show the preferential formation of Fe-oxide on the surface of oxidized Permalloy films, although the films are initially uniform alloys of $81 \% \mathrm{Ni}-19 \% \mathrm{Fe} .{ }^{10}$ The formation of the oxide is associated with the depletion of Fe from the bulk of the film. The depletion is not 10calized near the film surface, implying high diffusivity of $\mathrm{Fe}$ in $\mathrm{Ni}$ at remarkably low temperatures. ${ }^{11}$ 
From the magnetic moment and color of oxidized films of pure $\mathrm{Fe}$, it is concluded that the oxide is antiferromagnetic $\alpha-\mathrm{Fe}_{2} \mathrm{O}_{3}$. The fer romagnetic resonance results verify these conclusions and are only consistent with the presence of negligible pinning of the bulk spins at the film-oxide interface. The backscattering analysis also demonstrates the power of this new technique in solving problems of material transformations in the range of several thousand angstroms below the surface.

Having identified this oxidation process in Permalloy films, we are proceeding with a detailed study of its effects on resonance below room temperature and its implications for very thin Permalloy films $(L<100 \AA)$, whose characteristics show significant deviations from the bulk alloy, ${ }^{12}$ and the extent to which it can explain the properties of Permalloy films prepared in controlled oxygen environments. 13,14

*Work supported in part by Air Force Cambridge Research Laboratories and the Office of Naval Research.

${ }^{1}$ E. N. Mitchell and C. V. Briscoe, J. Appl. Phys. 37, 1489 (1966).

${ }^{2}$ F. B. Hagedorn, J. Appl. Phys. 38, 1362 (1967); 38, 3641 (1967).
${ }^{3}$ C. E. Patton and C. H. Wilts, J. Appl. Phys. 38, 3537 (1967).

${ }^{4}$ S. B. Bailey, T. M. Peterlin, R. T. Richard, and E. N. Mitchell, J. Appl. Phys. 41, 194 (1970).

${ }^{5} \mathrm{~J}$. W. Mayer, L. Eriksson, and J.A. Davies, Ion Implantation in Semiconductors (Academic, New York, 1970), Chap. 4.

${ }^{6} \mathrm{M}$. Hansen, Constitution of Binary Alloys (McGraw-Hill, New York, 1958), p. 684.

${ }^{7}$ M. H. Davies, M. T. Simnad, and C.E. Birchenall, J. Metals 3, 889 (1951).

${ }^{8}$ R. T. Foley, J. U. Druck, and R. E. Fryxell, J. Electrochem. Soc. 102, 440 (1955).

${ }^{9} \mathrm{~K}$. Hauffe, Oxidation of Metals (Plenum Press, New York, 1965), pp. 267, 310.

${ }^{10}$ In addition to $\mathrm{Ni}$ and $\mathrm{Fe}$, these films may initially also contain small amounts of impurities which result from their evaporation in a vacuum of $10^{-6}$ Torr. Specifically, it is plausible that some oxygen may also be present in the bulk of the unoxidized films.

${ }^{11}$ The mechanism by which $\mathrm{Ni}$ and $\mathrm{Fe}$ segregate upon oxidation cannot be determined from the backscattering spectra, but the simplest interpretation is to assume the migration of $\mathrm{Fe}$ through Ni before oxidation at the surface.

${ }^{12}$ M. H. Seavey, Jr, and P.E. Tannenwald, J. Appl. Phys. 29, 292 (1958).

${ }^{13}$ M. C. Paul and M. H. Hanson, J. Appl. Phys. 37, 3743 (1966).

${ }^{14}$ J. D. Blades, C.J. Lin, and R.A. Cola, J. Appl. Phys. 40,1567 (1969).

\title{
Comment on " $p$-Type Conduction in Li-Doped ZnSe"
}

\author{
J. Dieleman \\ Philips Research Laboratories, N.V. Philips' Gloeilampenfabrieken, Eindhoven, The Netherlands
} (Received 1 April 1971)

$p$-type conduction in $\mathrm{Li}$-doped $\mathrm{ZnSe}$ has been reported earlier, and the level at $0.62 \pm 0.02 \mathrm{eV}$ above the valence band observed in this material has been identified with trivalent Fe substitutionally incorporated on a $\mathrm{Zn}$ site.

The aim of this letter is threefold: (i) to show that the work of Park et al. ${ }^{1}$ is a repetition of part of earlier work on ZnSe and a confirmation of the earlier results; (ii) to point out that the acceptor level at about $0.66 \mathrm{eV}$ mentioned in the paper of Park et al. ${ }^{1}$ has been found previously and has been identified with a specific impurity; and (iii) to remark on the statement of Park et al. ${ }^{1}$ that "ZnSe appears to be a promising material among the II-VI compounds that can be made amphoteric by conventional doping techniques".

In 1966 Dieleman et al. reported about the acceptor action of alkali metals in II-VI compounds using $\mathrm{Fe}$ impurities as a Fermi-level indicator. ${ }^{2}$ This paper also contained evidence for the $p$-type character of ZnSe doped with Li, since it was shown that the Fermi level was at least $0.25 \mathrm{eV}$ below the middle of the forbidden zone of ZnSe. Later work of Dieleman $^{3}$ and Haanstra ${ }^{4}$ revealed that the incorporation of $\mathrm{Li}$ in $\mathrm{ZnSe}$ or the application of a Se pressure of some tens of a Torr resulted in $p$-type conductivity with carrier densities $<10^{10} \mathrm{~cm}^{-3}$ and the Fermi level located at a level at $0.62 \pm 0.02 \mathrm{eV}$ above the top of the valence band.

The paper of Haanstra ${ }^{4}$ supplied overwhelming evidence for the identification of this acceptor level with the level of the empty Fe donor in $\mathrm{ZnSe}$, i.e., in ionic language $\mathrm{Fe}^{3+}$ substitutionally incorporated on a $\mathrm{Zn}^{2+}$ site in $\mathrm{ZnSe}$. Since Fe is a trace impurity commonly encountered in $\mathrm{ZnSe},{ }^{5}$ it is not surprising that Park et al. found a similar level in their crystals.

Further research on $\mathrm{ZnSe}$ doped with alkali metals showed that the incorporation of large amounts of Li (100 ppm) and the concomitant application of a high Se pressure (10 atm) during the preparation of crystals did not bring the Fermi level further down than the above-mentioned level of the trace impurity $\mathrm{Fe}$, which means that $\mathrm{ZnSe}$ doped with $\mathrm{Li}$ does not seem to be a promising material, e.g., for the $p$ type part of a $p-n$ junction for injection luminescence purposes. 